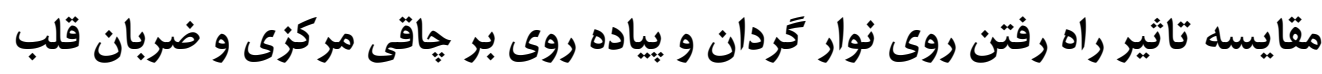

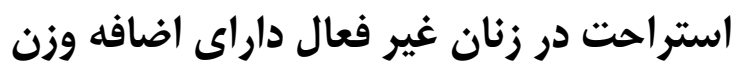

$$
\text { زهره دلفانى *'، فرشته شهيدى' }
$$

ا) كروه فيزيولوزى ورزشى، دانشكده تربيت بدنى، دلنشكاه تربيت دبير شهيد رجايى، تهرلن، إيران

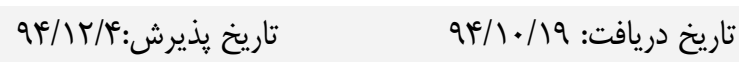

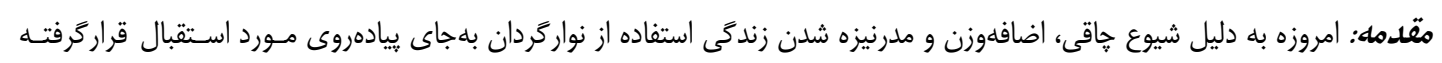

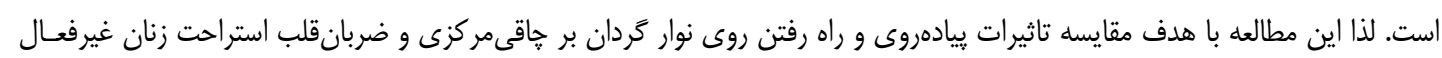
داراى اضافلوزن شهرستان بروجرداجرا گرديده است.

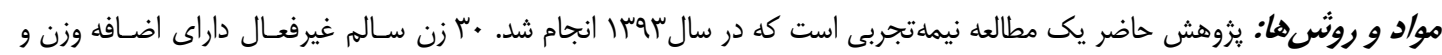

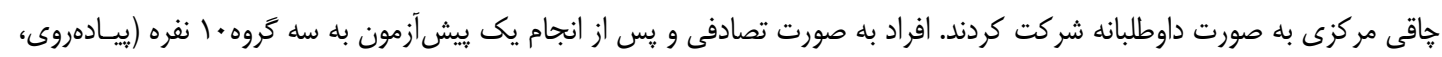

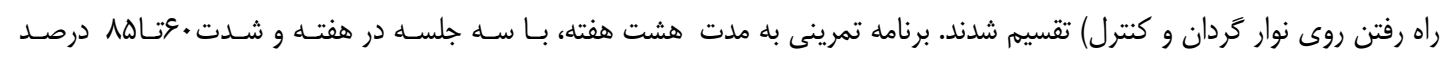

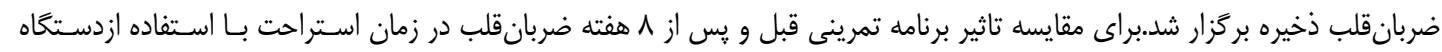

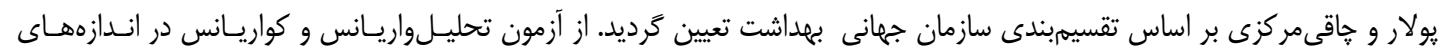

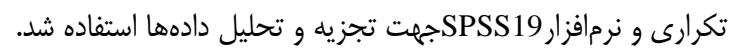

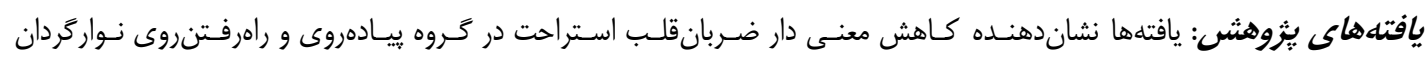

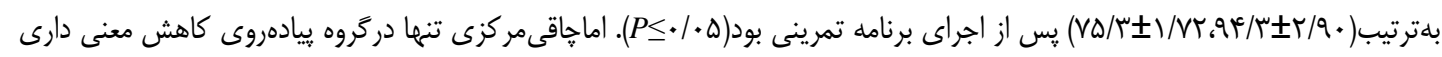

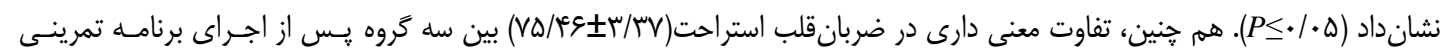

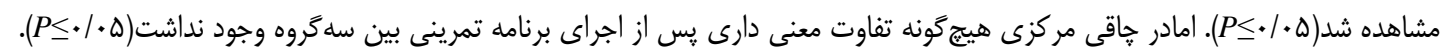

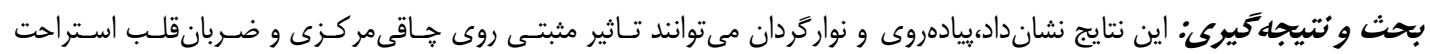

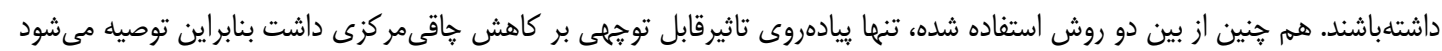

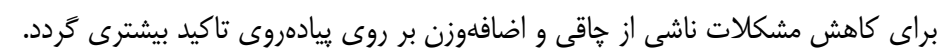

وازههاى كليدى: پيادهروى، نوار گردان، اضافهوزن، ضربانقلب استراحت، جاقىمركزى.

$$
\text { * نويسنده مسئول: گروه فيزيولوزى ورزشى، دانشكده تربيت بدنى، دانشگاه تربيت دبير شهيد رجايى، تهران، ايران }
$$

Email:Delfaniz@ymail.com

Copyright (c) 2017 Journal of Ilam University of Medical Science. This is an open-access article distributed under the terms of the Creative Commons Attribution international 4.0 International License (https://creativecommons.org/licenses/by-nc/4.0/) which permits copy and redistribute the material, in any medium or format, provided the original work is properly cited. 
منــازل آيارتمـانى نيـز بــهـ عنــوان فهـاليتى جـايخزين

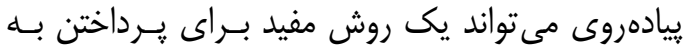

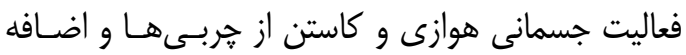

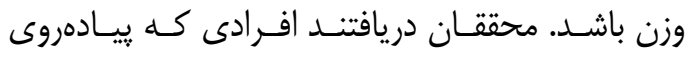

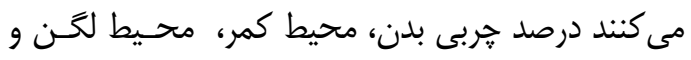
نسـبت دور كمـر بـه باسـن (Waist-to-Hip Ratio)

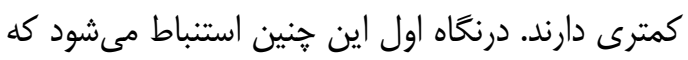

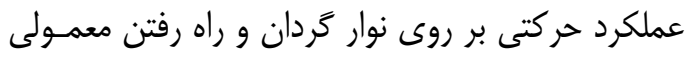

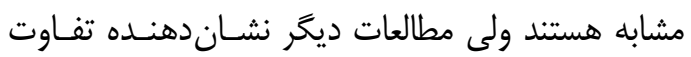

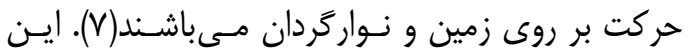
مسئله از اين نظر حائز اهميت است كه در مطالعاتى كه

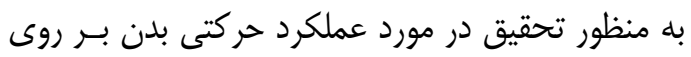

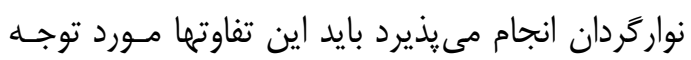

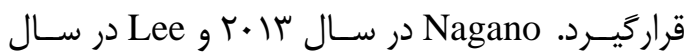

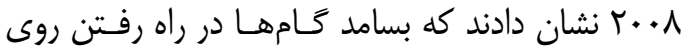

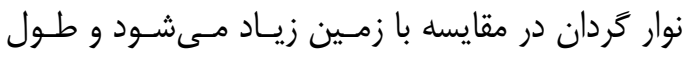

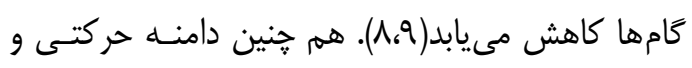
حداكثر زاويه فلكشن مفصل لكن و ضرباهنَ

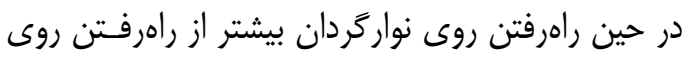

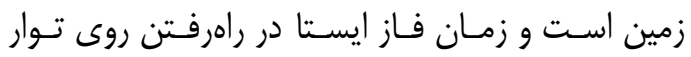

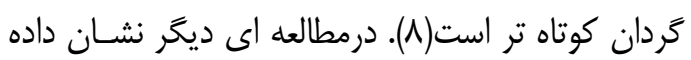

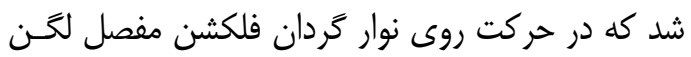
در فـاز نوسـانى و فلكشـن زانـو در فـاز ايسـتا بيشـتر

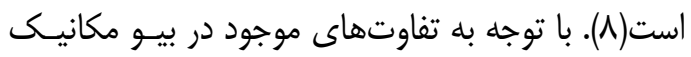

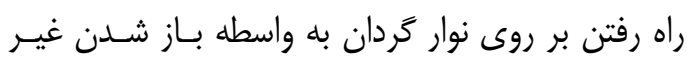

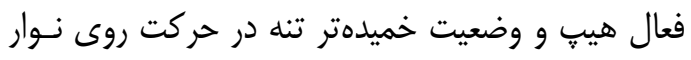

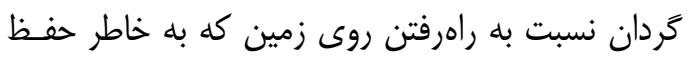

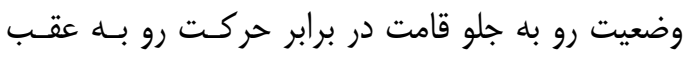

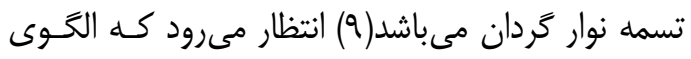

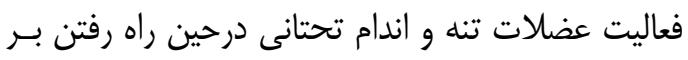

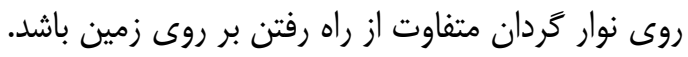

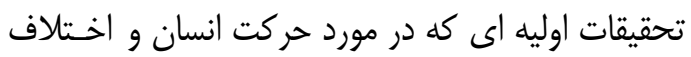

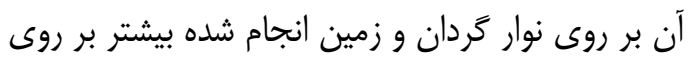

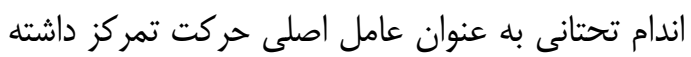

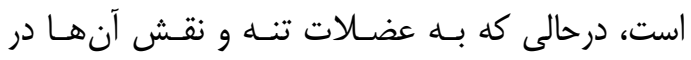

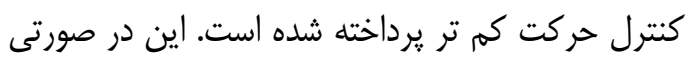
است كه تنه •و٪ توده عضلانى بدن را را تشكيل مى دهند

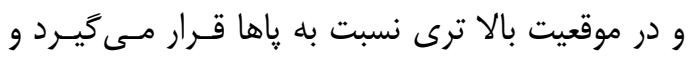

مقدمه:

بيشرفت صنعت، فعاليـت جسـمانى را در طـى خنــدين

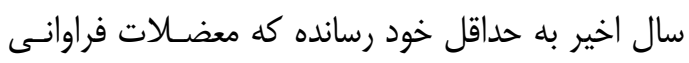

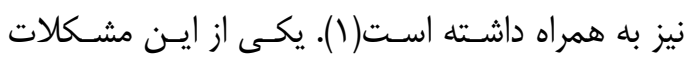

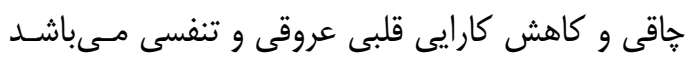

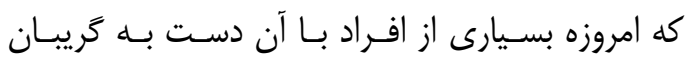

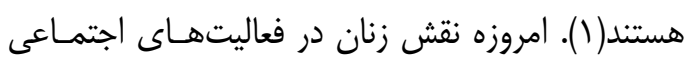

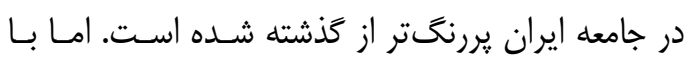

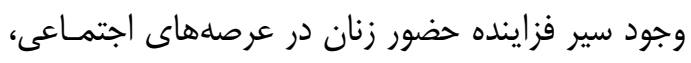

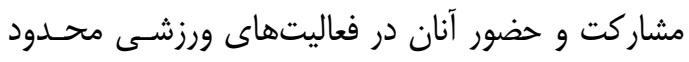

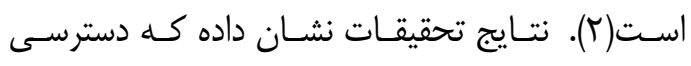

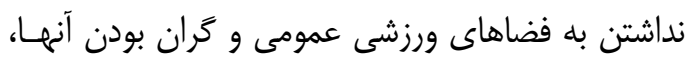

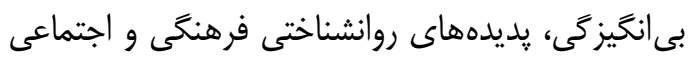

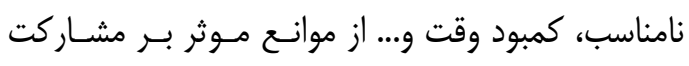

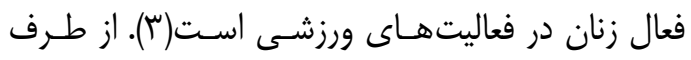

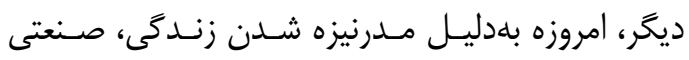
شدن جوامع و هم زمـان بـا توسـعه فرهنــ آيارتمـان

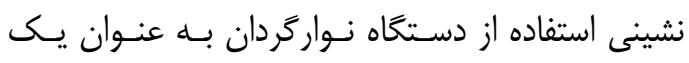

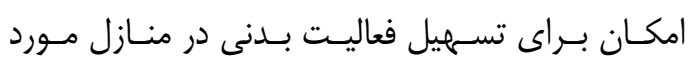

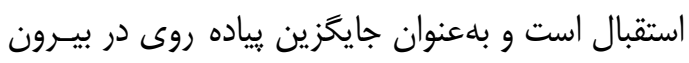
خانه توصيه مى شود. حال اين سوال مطرح است كه آيا

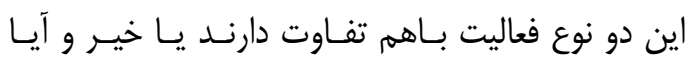
مى توان از اين دو روش به جاى هم اسـتفاده كـرد؟(أ).

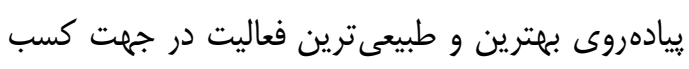

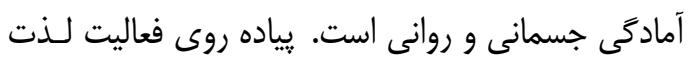

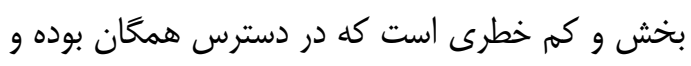

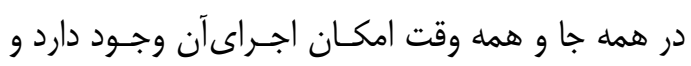

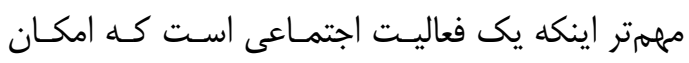

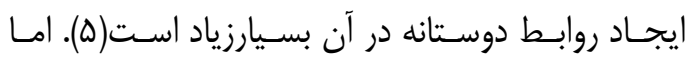

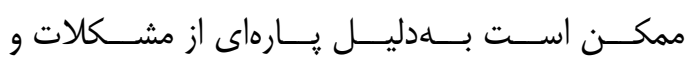
محدوديتهاى خاص يياده روى در محيطهاى طبيعى لئس

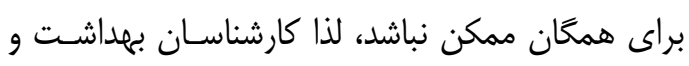

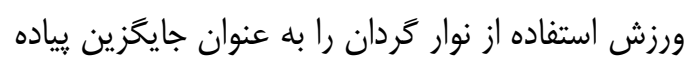

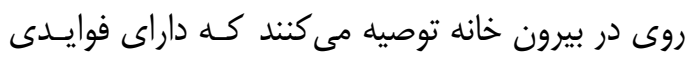

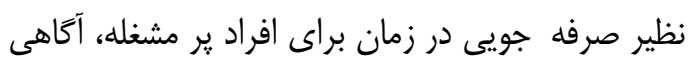

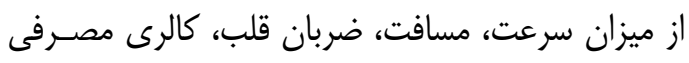

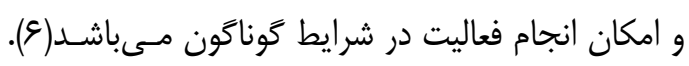

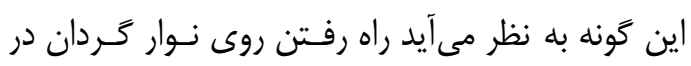




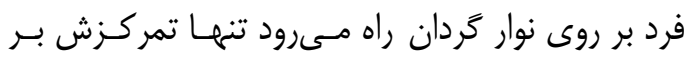

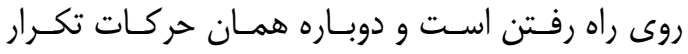
مىشود، اما هنكامى كه در محـيط بيــرون بـراى يَيـاده

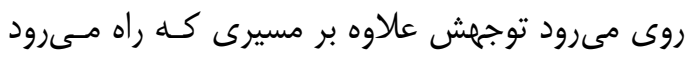

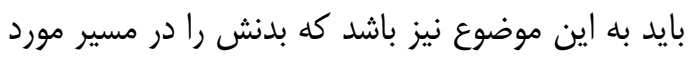
نظر به جلو براند. در يِياده روى ميزان و بلندى كامهايى بإيى كه فرد بر مىدارد نيز بسيار مهرم هستند. البته در يياده

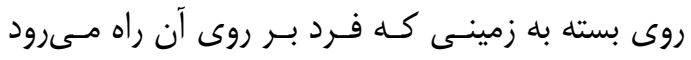

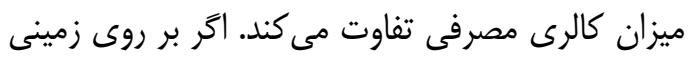

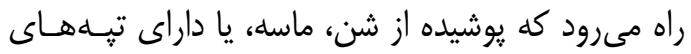
بلند و كوتاه باشد، مسله است كه ميزان كالرى مصرفى

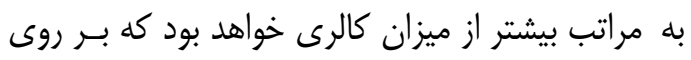

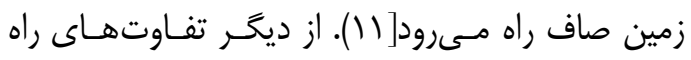

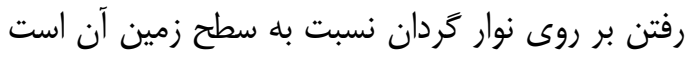

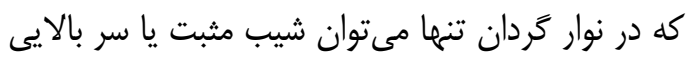

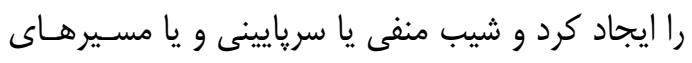

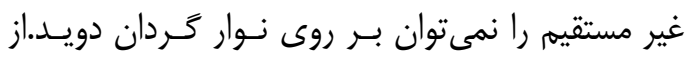

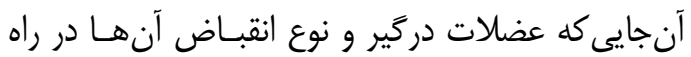
رفتن در سر بالايى و سر پايينى و سطوح غير مستقيم

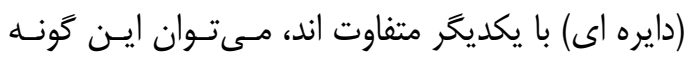
نتيجه كيرى كرد كه راه رفتن در سطوح طبيعى (داراى يستى و بلندى و مسيرهاى منحنى) سبب بـهـــارگيرى تعداد بيشترى از عضلات نسبت بـهـ راه رفـتن بـر روى

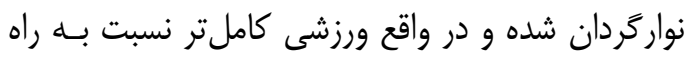
رفتن برروى نوار كردان است.از طرف ديخر وجود همين

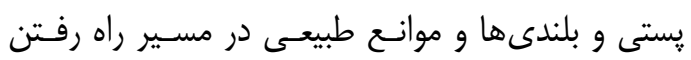
سبب هماهنكى بيشتر عصبى- عضلانى در ياها شده و

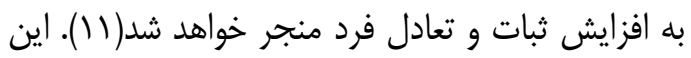

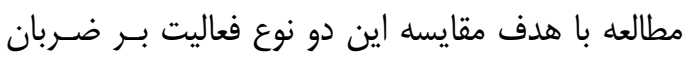
قلب استراحت و هاقى مركزى زنـان غيــر فعـال داراى

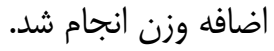

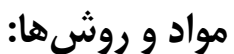

اين مطالعه از نوع كاربردى با طرح نيمه تجربى كـهـ در

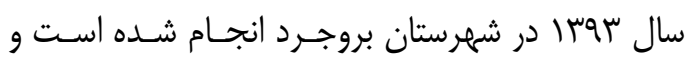

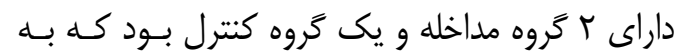

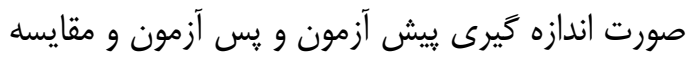

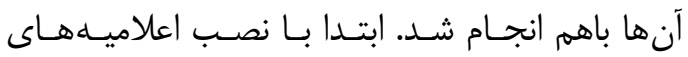

نقـش مهمـى را مانتــد يـك پانـدول معكـوس اعمـال مىنمايد. تنه تعــداد زيـادى مفصـل دارد و از عضـلات

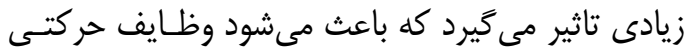

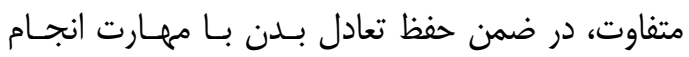

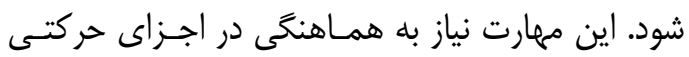
تشكيل دهنده تنه دارد تا تركيبى از فعاليتهـاى هـيش

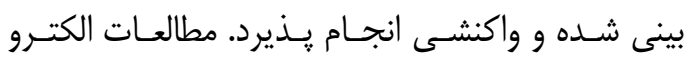

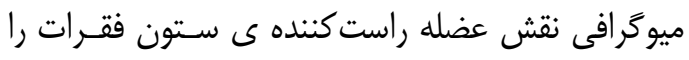

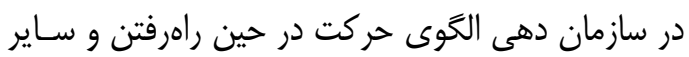
فعاليتهاى حركتى ريتميك برجسته كرده اسـت( •(1).

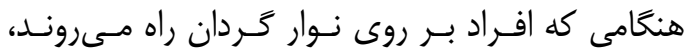

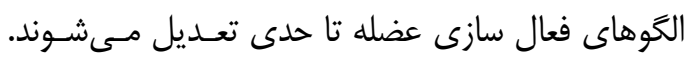

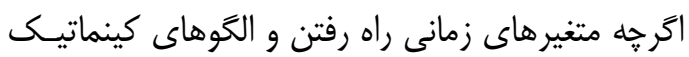
ميان راه رفتن روى زمين و نوار خــردان مشـابه اسـت، الكوهاى فعال شدن عضله و گشتاورها و نيروهاى مون مورد

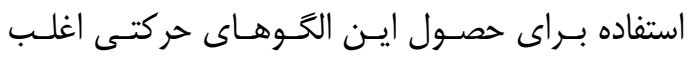
متفاوت هستند. Warabi و همكاران در سال هـ م. -ب نيز نشان دادهاند كه نيروى واكنش در ييـاده روى بـر روى

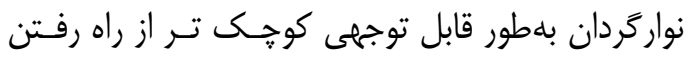

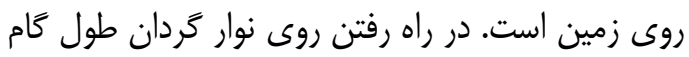

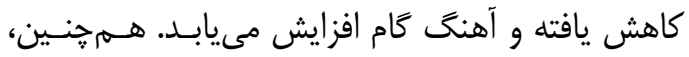
زمان تماس از ياشنه يا بر روى نواركردان نسبت بــهـ راه رفتن روى زمين كوتاه تر مىشود (V) بنـابراين، انتظـار

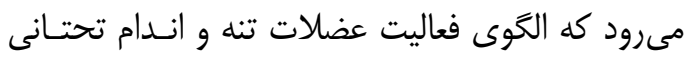
درحين راه رفتن بر روى نوار گردان متفاوت از راه رفتن فئن

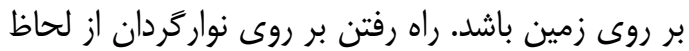

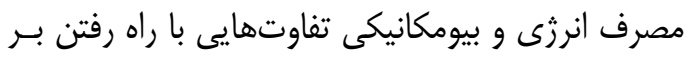

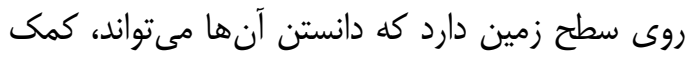

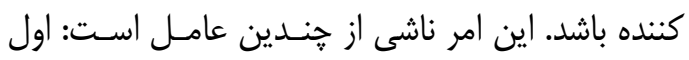

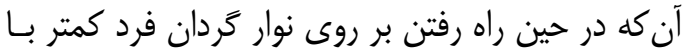

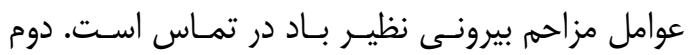

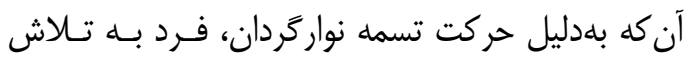

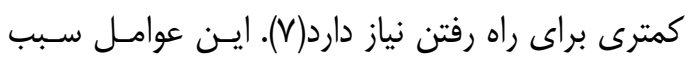
مىشود راه رفتن و دويدن بر روى نوار كردان نسبت به نيه سطح زمين نيازمند صرف انرزى كم تـرى باشــ(9). در

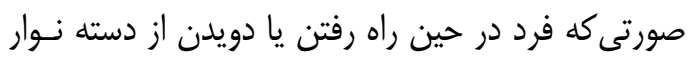

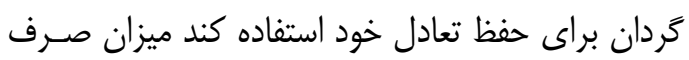
انرزى از اين ميزان نيز كمتر مىشـود[ه]. هنَــامى كـهـ 
شديد باشد، طراحى شده است و شامل V سوال با ياسخ

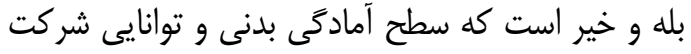

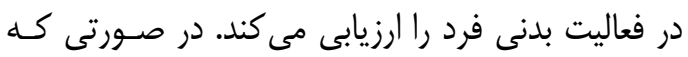

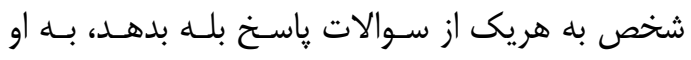

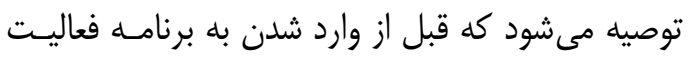

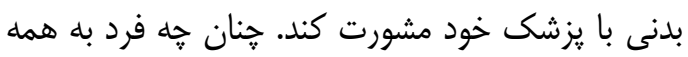

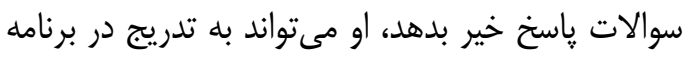

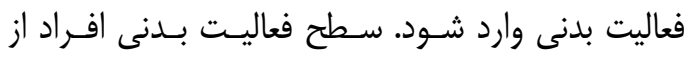

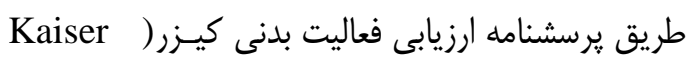
Physical Activity Survey

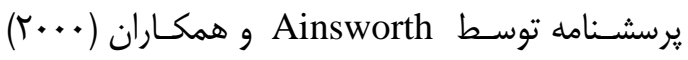

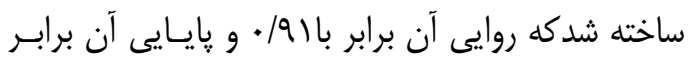

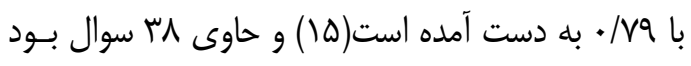

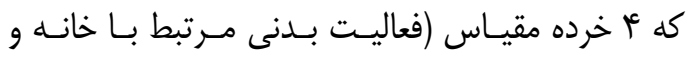

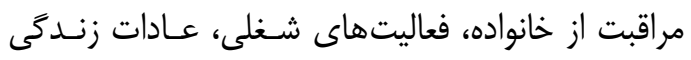

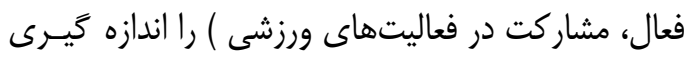

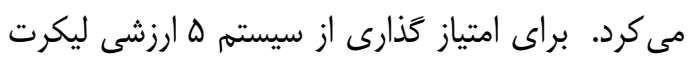

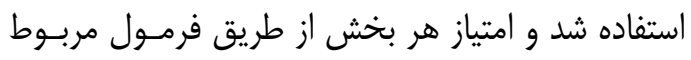

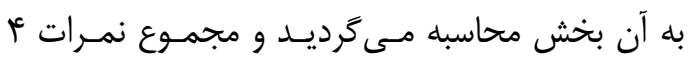

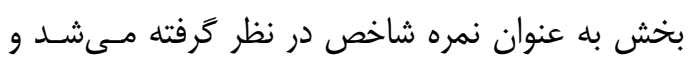

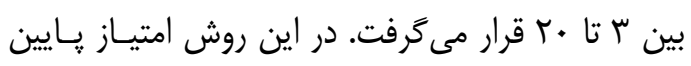

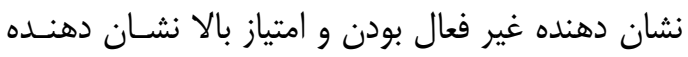

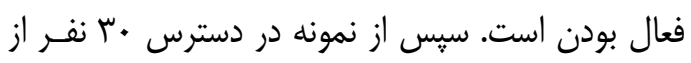

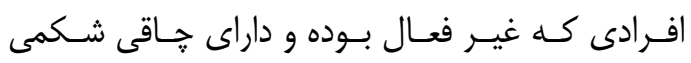

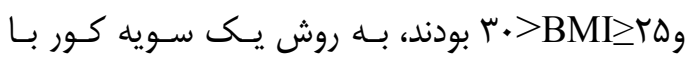

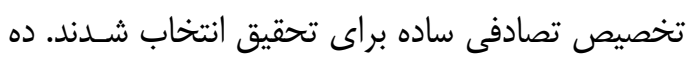

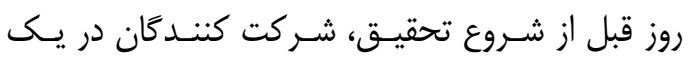
جلسه آشناسازى شركت داده شدند و بــهـ آنهــا نكـات

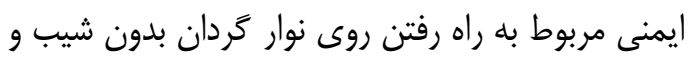

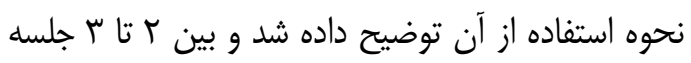

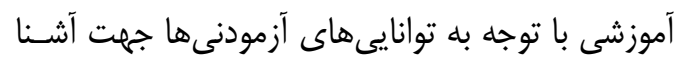

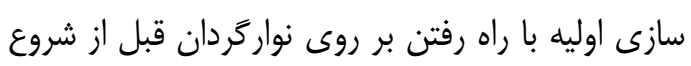
تمرينات در نظر كرفته شد. اما در باره كى روند تمرينات

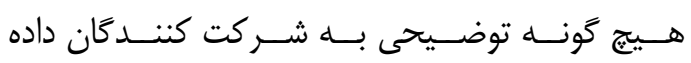

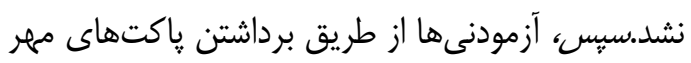

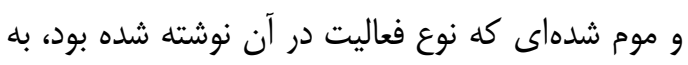

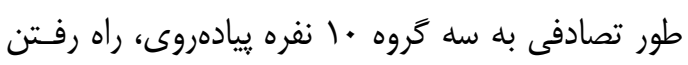

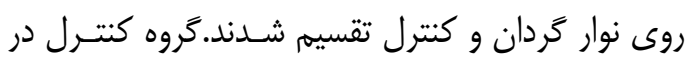

فراخوان در سطح شهر بروجرد، افراد داراى اضـافه وزن

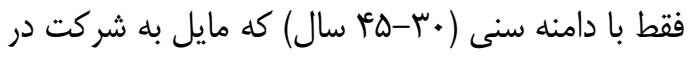
طرح يزوهشى بودند، توسط محقق شناسايى شدند. زيرا

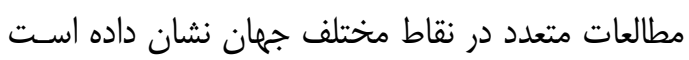
كه آماده سازى كسانى كـه در حـال حاضـر در ســنين

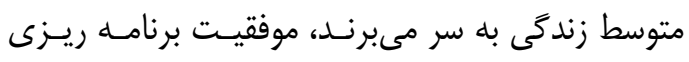

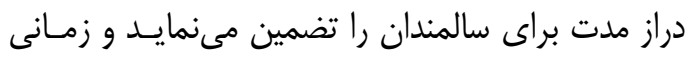

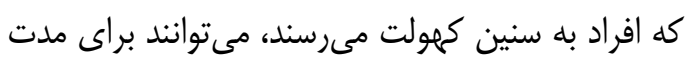

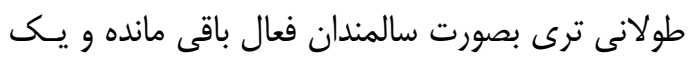

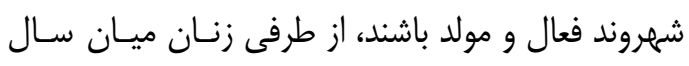

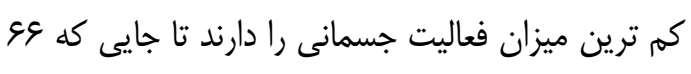

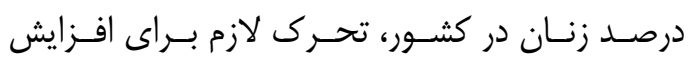

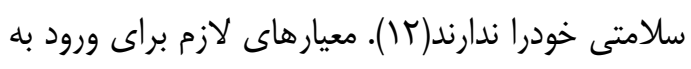
مطالعه جنس مونث، داشتن جاقى مركزى ( نسـبت دور

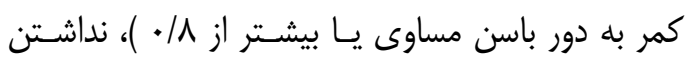
تحرك بدنى؛ به معنى نداشتن حداقل •ب دقيقه فعاليت

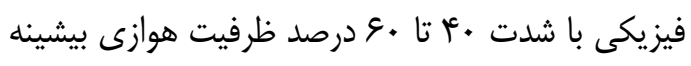

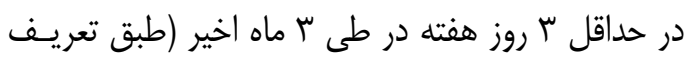

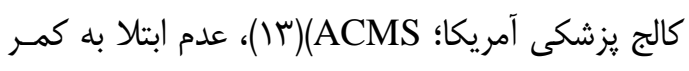

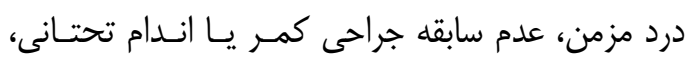

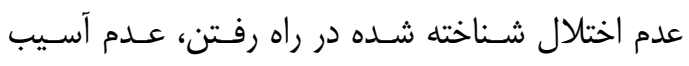
نورولوزيك، و نداشتن بيمارى هاى قلبـى عروقـى بـود.

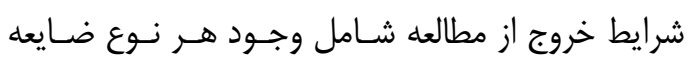

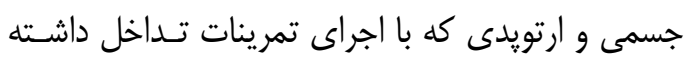
باشد و مانع از اجراى تمرينات با كيفيت لازم شود، بود.

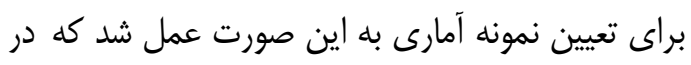

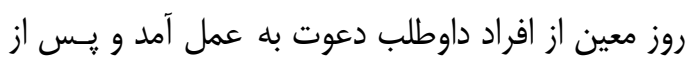

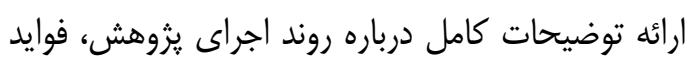

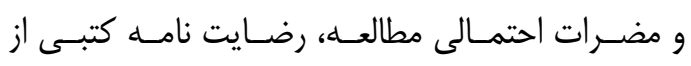

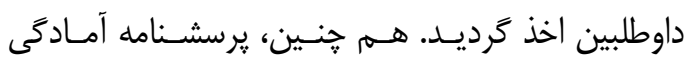

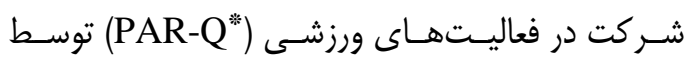

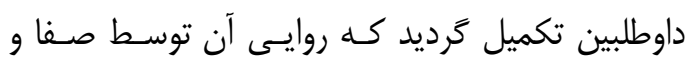

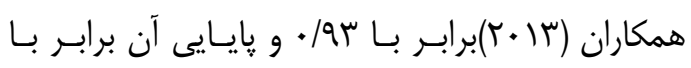

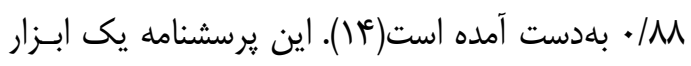

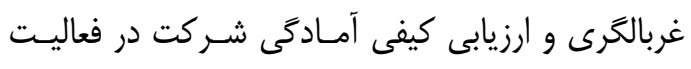

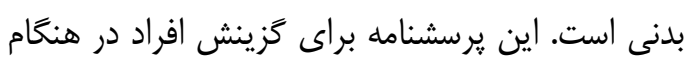
شركت در فعاليتهاى جسمانى كه مىتواند براى آنهـا

*-Physical Activity Readiness Questionnaire 
استراحت قبل و بعد از انجام مداخله در هـر ســـ حَروه

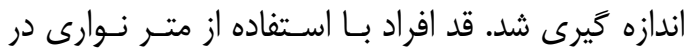
وضعيت ايستاده و بدون كفش در حالى كه كتـفهـا در

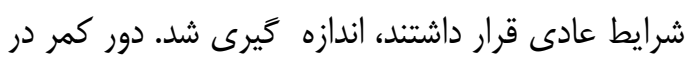

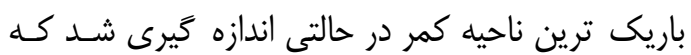
فرد در انتهاى بازدم طبيعى خـود بــود. از آزمـودنى هـــا خواسته شد لباسهايى كه منجر به تغييـر شـكل بـدن

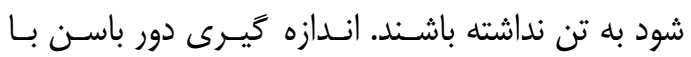

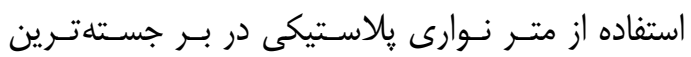
قسمت بدون تحميل هر گَونه فشارى به بلن با خطاى

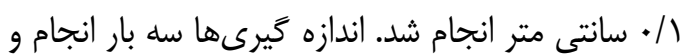

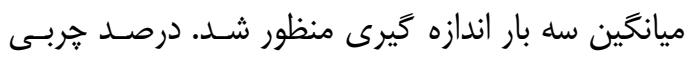

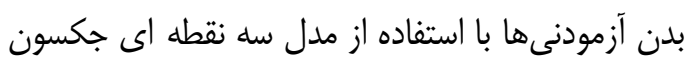

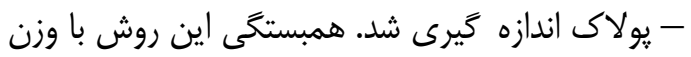

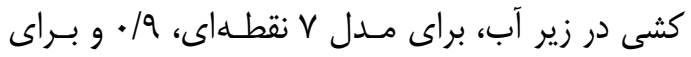

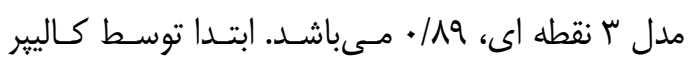

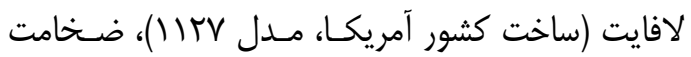

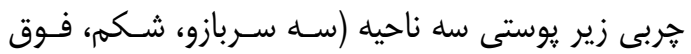

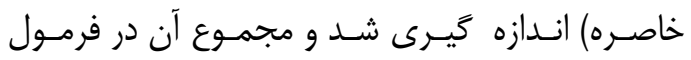

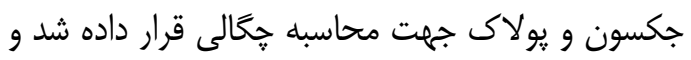

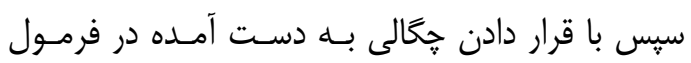

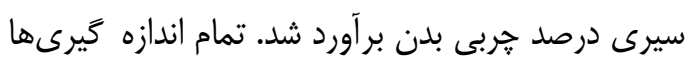

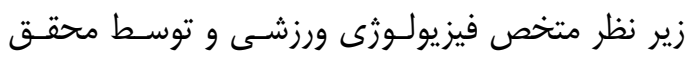

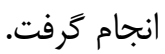

سه سر بازو+ شكم + فوق خاصره

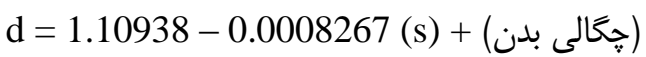
$-0.0002574($ age $\left.) \mathrm{g} / \mathrm{cm}^{2}\right)\left(0.0000016(\mathrm{~s})^{2}\right.$ درصد جربى بدن (فرمول سيرى) 40 - $400=\frac{4.95}{d}$ براى اندازه گَيرى ضربان قلب در حـال اسـتراحت فـرد هادقيقه در حال استراحت مطلق به صورت نشسته قرار مى مَرفت. سيس ضربان قلب به وسيله ى ضر ضربان سنج

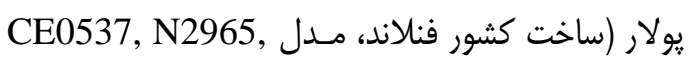

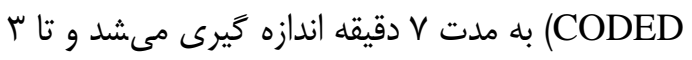
دقيقه آخر به كم ترين حد مىرسـيد. در ب دقيقهـ آخـر

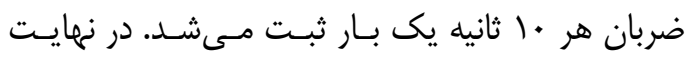

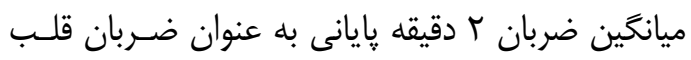

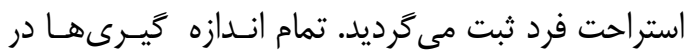

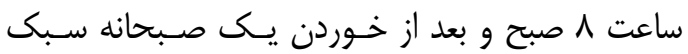

اين دوره فعاليت ورزشى خاصى نداشتند. برنامه تمـرين ب روز در هفته به مدت \ هفته و از نوع فزاينده بود.

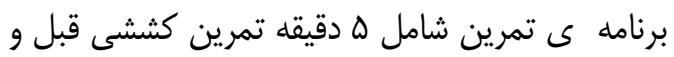

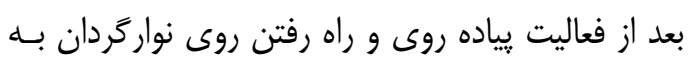

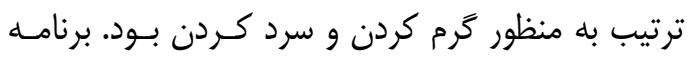

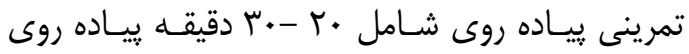

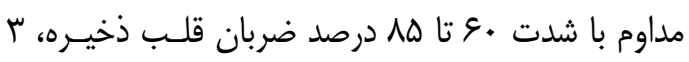

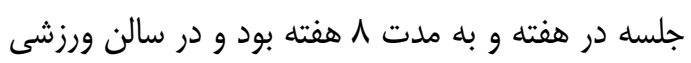

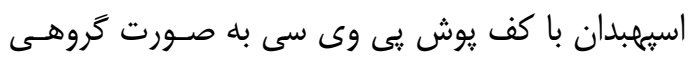

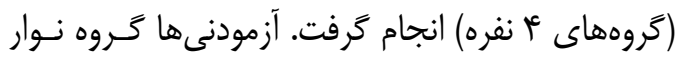
كردان در همان سالن ورزشى فعاليـت خـود را بـر روى إنى

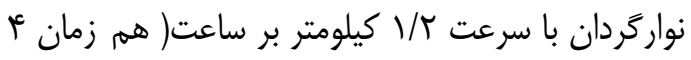

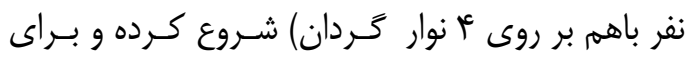
حفظ شدت تمرين در محدوده تعيين شده سـرعت نـوار

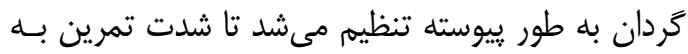

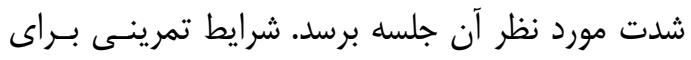

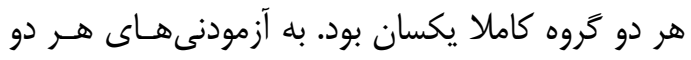
كروه توصيه شــد در طـول ^ هفتـهـ اجـراى تمـرين از شركت در هر گونه فعاليت ورزشى ديخر خوددارى كنند.

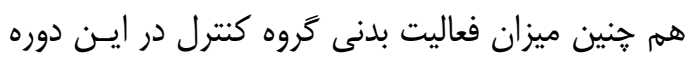

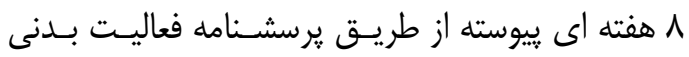

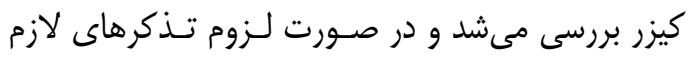

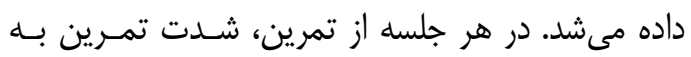

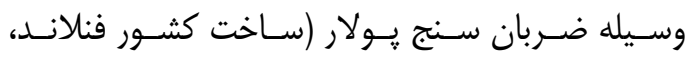
مدل) كنترل مىشد شدت فعاليت از طريق ضربان قلب ذخيره ((ضـربان

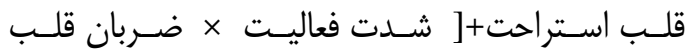

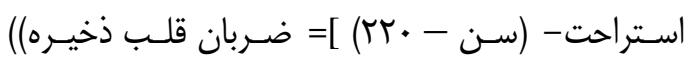
محاسبه كرديد. هفته اول شدت فعاليت •ع تا هو در درصد ضربان قلب ذخيره براى مدت • r دقيقه بود كه تا يايان

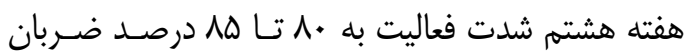

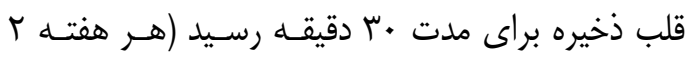

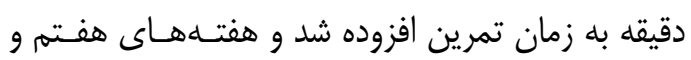

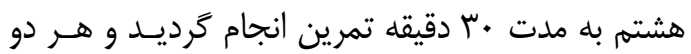

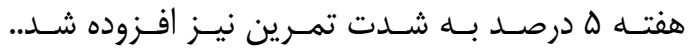

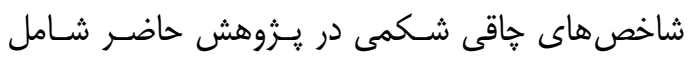

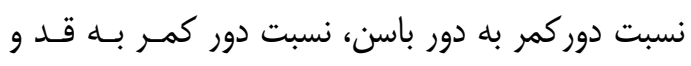

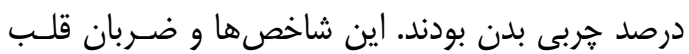


ميزان تفاوتهاى مقادير متغيرهاى آنتـرو يـومتريكى و فيزيولوزيكى بين سه كَروه پِ از اجراى برنامه تمرينى ارائه شده است. نتايج يزوهش نشان داد نسبت دور كمر

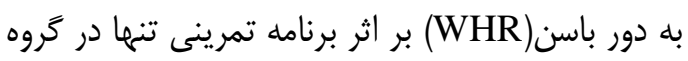

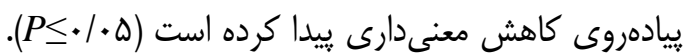
اگرجه در شاخص نسبت دور كمر به باسن(WHR)بين

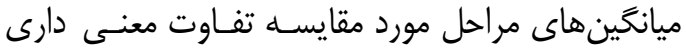

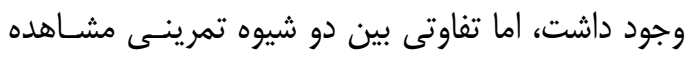
نشد. شاخص نسبت دور كمر به قد در گروه ييـاده روى و راه رفتن روى نواركردان كاهش معنادارى نشـان داد،

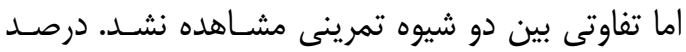

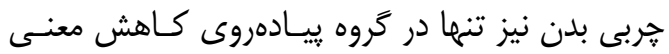

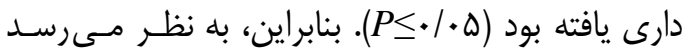
كاهش جاقى شكمى در گــروه ييـاده روى بــه دليـل از دست دادن توده جربى بيشتر در ناحيـه سـرينى اسـت.

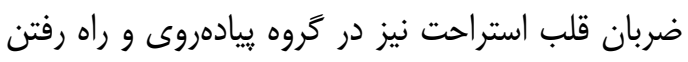

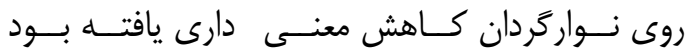

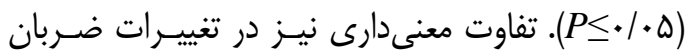
قلب استراحت بين سه كروه وجود داشت، به طورى كـهـ

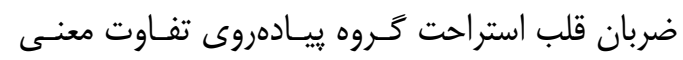

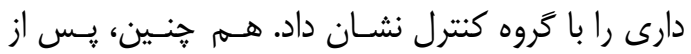

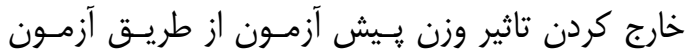
تحليـل كواريـانس، تفـاوت معنسى دارى بـين ميـانگين ضربان قلب استراحت سه كَروه در پِ آزمون مشـاهده
انجام شــــ از آزمــون كلمـوَّروف - اسـميرنوف بــاى نشان دادن توزيع طبيعى دادهها و آزمـون لـوين بـراى

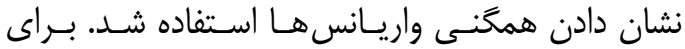

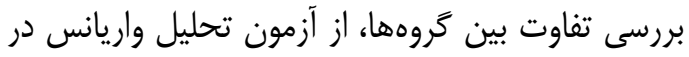

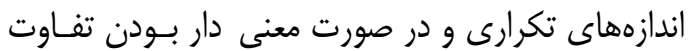

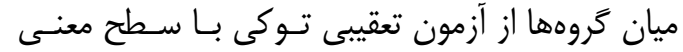

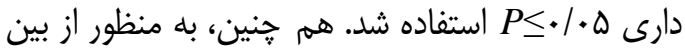

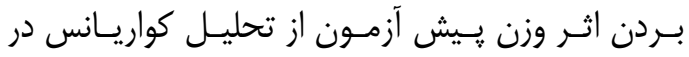

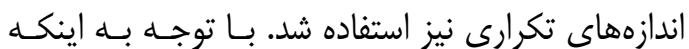

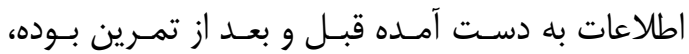

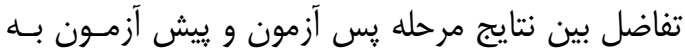

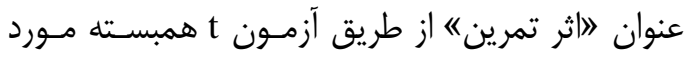

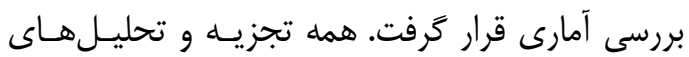
آمارى با نرمافزارSPSS ويرايش 19 انجام شد.

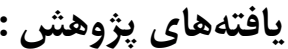

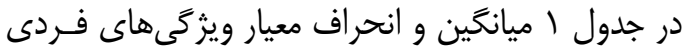

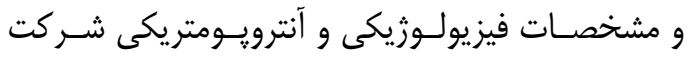

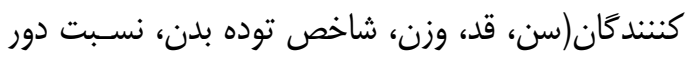

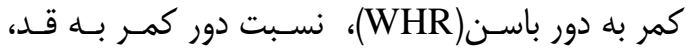
درصد هربى، ضربان قلب استراحت) ذكر كَرديده اسـت. مقادير متغير وابسته در هر تروه در جدول بر ارائه شـده

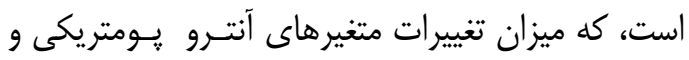

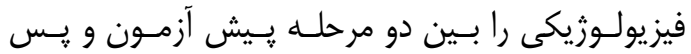

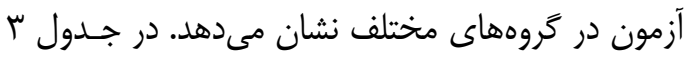

جدول ( - مشخصات آنترو يومتريكى و فيزيولوزيكى آزمودنىها

\begin{tabular}{|c|c|c|c|c|c|c|c|c|c|}
\hline $\begin{array}{c}\text { ضربان قلب استراحت } \\
\left(\text { bpm }^{-1}\right) \\
\end{array}$ & نسبت دور كمر & $\begin{array}{c}\text { WHR } \\
\text { (نسبت دور كمر به باسن) }\end{array}$ & درصد خربى & $\begin{array}{c}\text { شاخص توده بلن } \\
f^{-} \text {(kg.m }\end{array}$ & $\begin{array}{l}\text { وزن(كيلوكرم) } \\
\bar{X} \pm S D\end{array}$ & $\begin{array}{l}\text { قد(سانتى متر) } \\
\bar{X} \pm S D\end{array}$ & $\begin{array}{l}\text { سن(سال) } \\
\bar{X} \pm S D\end{array}$ & تعداد & كروه \\
\hline$V \wedge / q \pm Y / \Lambda f$ & $+/ 09 \pm+1+r$ & $+/ \Lambda \Lambda \pm+\mid+f$ & $r v / q r \pm \Delta / r+$ & $r \vee / \& \Lambda \pm I / r \Lambda$ & $8 q / 9 \pm r / 1$ & $\begin{array}{l} \pm f / 1 q \\
109 / f\end{array}$ & سT/• & 1. & نواركردان \\
\hline$\vee q / ı \pm r / V \Delta$ & $+|8| \pm+1+8$ & 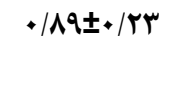 & $r q / V r \pm \Delta / \Delta r$ & $r \vee / \Lambda \Lambda \pm I / I T$ & $8 q / \Lambda \pm r / \Lambda r$ & $\begin{array}{l} \pm r / 10 \\
1 \Delta \Lambda / \Lambda\end{array}$ & r $/ \mathbf{q} \pm q / r$. & 1. & ييادمروى \\
\hline$V q / r \pm r / V^{c}$ & $+|\Delta \Lambda \pm+|+r$ & $\cdot / \Lambda \Lambda \pm+/ T \Lambda$ & $r \wedge / r) \pm r / f q$ & $r V / \& T \pm I / I T$ & $q q / 1 \pm r / 1 V$ & $\begin{array}{l} \pm F / q \psi \\
1 \Delta \Lambda / V\end{array}$ & rq/1 $\pm 11 / \wedge 9$ & 1. & كنترل \\
\hline
\end{tabular}




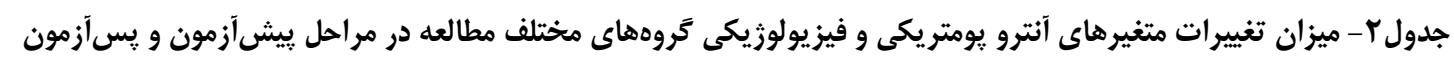

\begin{tabular}{|c|c|c|c|c|c|c|c|c|c|}
\hline & \multicolumn{4}{|c|}{ تحروه نوارتحردان } & \multicolumn{3}{|c|}{ تحروه بِيادهروى } & \multicolumn{2}{|l|}{ تحروه كنترل } \\
\hline $\mathrm{T}$ & 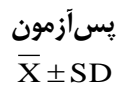 & $\begin{array}{c}\text { بيش آزمون } \\
\bar{X} \pm \text { SD }\end{array}$ & $\mathrm{T}$ & 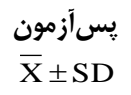 & 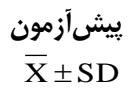 & $\mathrm{T}$ & $\begin{array}{l}\text { ֶسآزمون } \\
\bar{X} \pm \text { SD }\end{array}$ & $\begin{array}{c}\text { بيشآزمون } \\
\bar{X} \pm \text { X }\end{array}$ & متغير ها \\
\hline$*_{T / T V D}$ & $\cdot \mid \Delta t \pm \cdot / \cdot t$ & $\cdot / \Delta 9 \pm \cdot / \cdot r$ & $*_{r / q q \mu}$ & $\cdot / \Delta \Delta \pm \cdot / \cdot \Delta$ & $.|9| \pm .1 .9$ & T/Tr. & $\cdot / D T \pm . / \cdot T$ & 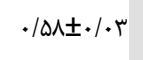 & نسبت دور كمر به قد \\
\hline $1 / 1 \cdot v$ & $\cdot \mid N \& \pm \cdot / \cdot r$ & $\cdot \mid \Lambda \Lambda \pm \cdot / \cdot r$ & שחז/T* & $\cdot \mid \wedge \& \pm \cdot / \cdot r$ & . &.$/ 494$ & $\cdot \mid M \pm \cdot / \cdot r$ & $\cdot / M \pm \cdot / r$ & ور كمر به بان \\
\hline
\end{tabular}

|WHR|

درصد جربى بدن

ض ضربان قلب استراحت $\left(\mathrm{bpm}^{-1}\right)$

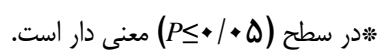

جدول س- نتايج آزمون تحليل واريانس و تحليل كواريانس در اندازههاى تكرارى WHR، درصد خربى بدن، نسبت دور كمر به قد،

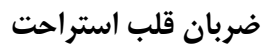

\begin{tabular}{|c|c|c|c|c|c|c|}
\hline سطح متنادرى (P) & آماره آزمون (F) & درجه آزادى (df) & منبع تغييرات & $\overline{\mathrm{X}} \pm \mathrm{SD}$ & مرحلd & آزمون \\
\hline$+1+m f$ & $*_{\Delta / \cdot I V}$ & 1 & عامل مرحله & $\cdot / \wedge 9 \pm \cdot / \cdot r$ & يِيشآزمون & WHR \\
\hline$+|f|$ & . /9Tr & $r$ & F كوليت F & $\cdot / \Lambda \vee \pm \cdot / \cdot r$ & يسآزمون & \\
\hline + /VFV & 年 & r & عامل تروه & & & \\
\hline$\cdot / \cdot V$ & 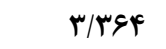 & 1 & عامل مرحله & $r V / ৭ q \pm r / \wedge \Lambda$ & & درصد گربى بدن \\
\hline & & & & $r \Delta / v q \pm \boldsymbol{r} / l)$ & ييشآزمون & \\
\hline. $\mid F+1$ & - AAFD & r & كوليت F F & & يسآزمون & \\
\hline.$/ 190$ & פשr/ו & r & عامل تروه & & & \\
\hline$+1++$ & *IV/aW & 1 & عامل مرحله & $\cdot / \Delta q \pm \cdot / \cdot{ }^{c}$ & يِشآزمون & نسبت دور كمر به قد \\
\hline מגומן &.$/ 198$ & r & كوليت & $\cdot \mid \Delta f \pm \cdot / \cdot r$ & يسآزمون & \\
\hline$\cdot / r q q$ & $1 / 494$ & r & عامل تروه & & & \\
\hline$+1++$ & $*^{T \cdot / 19 Q \Delta}$ & 1 & عامل مرحله & $\vee q / \cdot \varnothing \pm \Psi / q q$ & يِيش آزمون & ضربان ثلب استراحت \\
\hline$+1++$ & $*^{t h / A T t}$ & r & كوليت F & $V \Delta / F \& \pm \Psi / r V$ & يس آزمون & \\
\hline$+1++1$ & $*_{\Delta / \mathrm{V} \wedge \mathrm{V}}$ & r & عامل تروه & & & \\
\hline
\end{tabular}

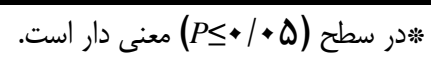

روى نوار گردان بـراى بهبـود و كـاهش ضـربان قلـب

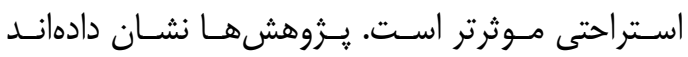
تمرينات هوازى موجب كاهش ضربان قلـب اسـتراحتى مهـى

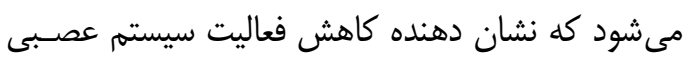

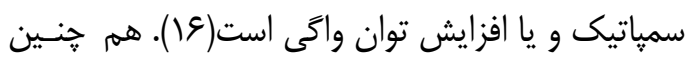
ييشنهاد شده است كاهش ضربان قلب استراحتى ناشى از فعاليت ورزشى ممكن است ناشى از سازگًارى در خود

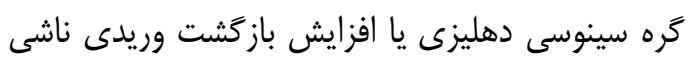

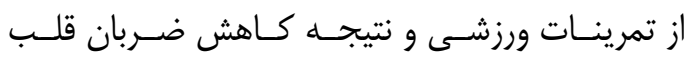

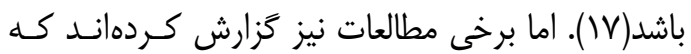

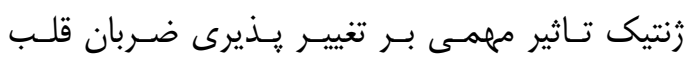

\section{: بحث و نتيجه كيرى}

يافته هاى يـرثروهش حاضـر حـاكى از كـاهش معنـى دار ضربان قلب استراحت در گروه تجربسى ييـادهروى و راه

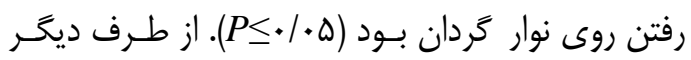

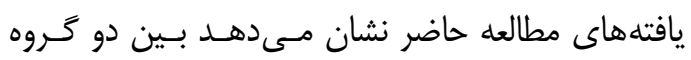

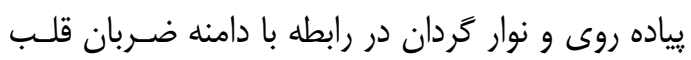
استراحت، قبل و بعد از ^ هفته فعاليت ييـاده روى و وراه رواه رفتن روى نوارگردان تفاوت معنىدارى وجود دارد. ايسن بـن

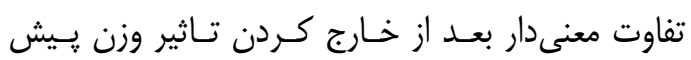

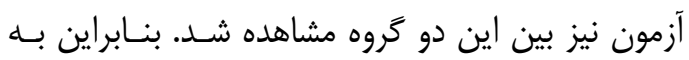

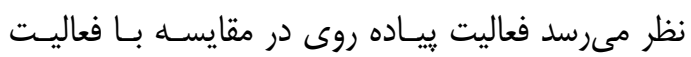


ضربان قلب استراحت، زمان بيشترى جهـت يـر كـردن

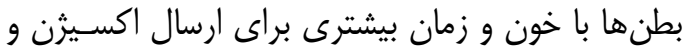

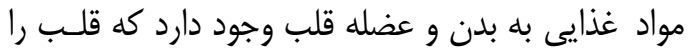

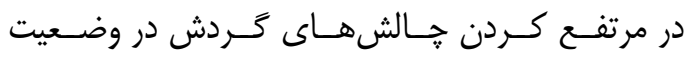

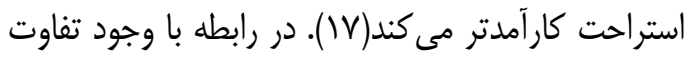

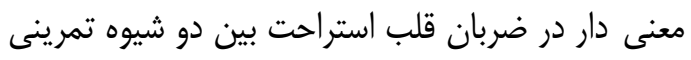

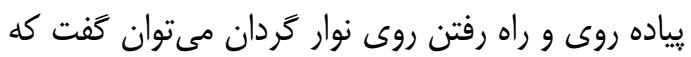

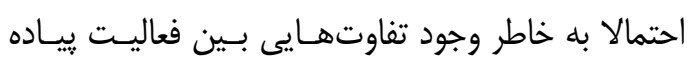

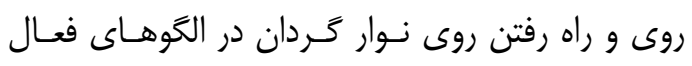

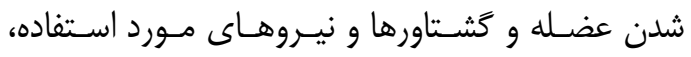

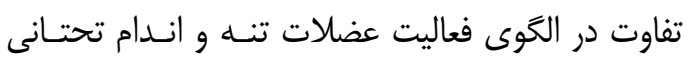

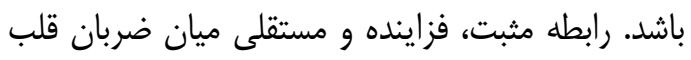

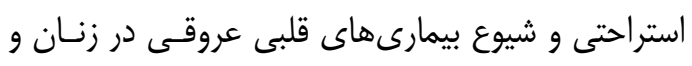

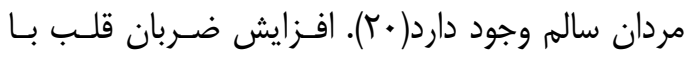

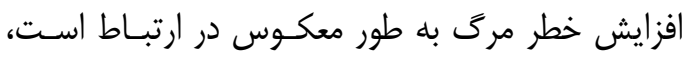

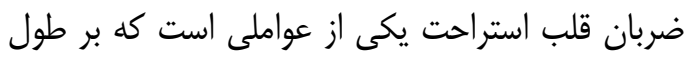

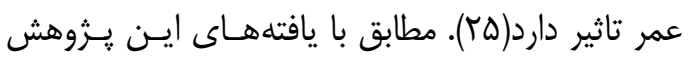

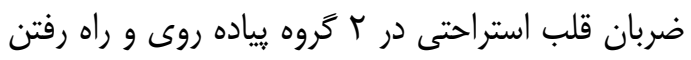
روى نواركردان كاهش يافته و در سـاير تحقيقـات نيـز

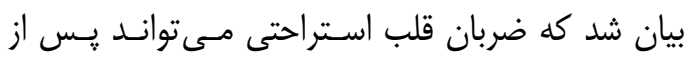

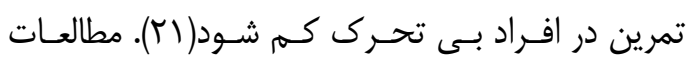

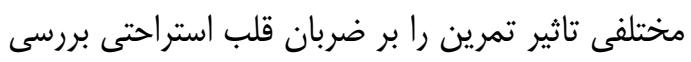

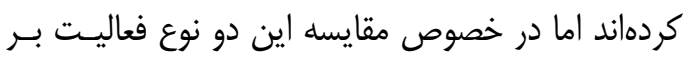
ضربان قلب استراحتى در افراد سالم، تحقيقـاتى بسـيار

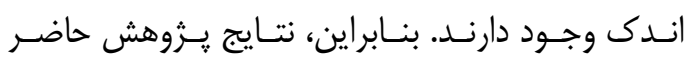

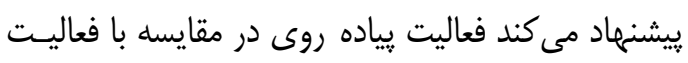

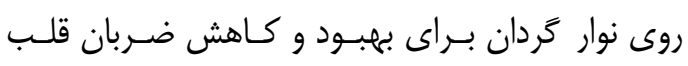

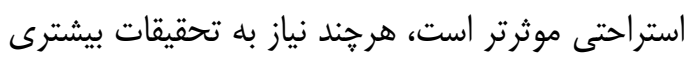
است.

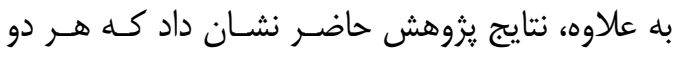
فعاليت باعث كاهش معنى دار شاخص نسبت دور كمـر

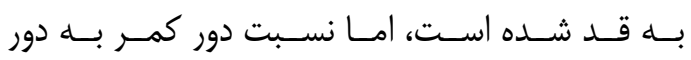

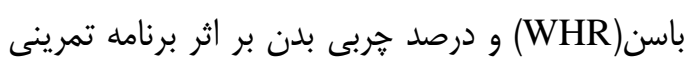

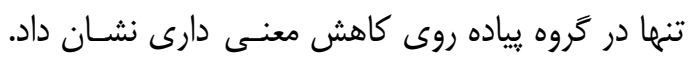

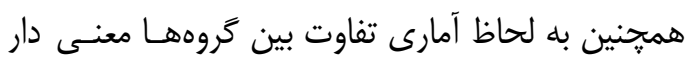

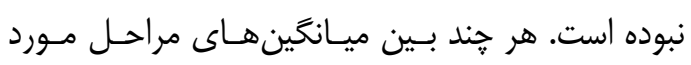

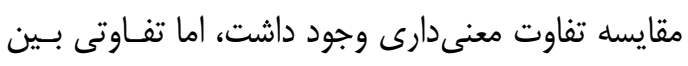

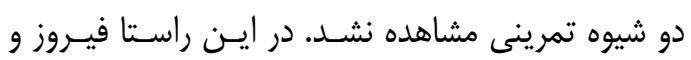

استراحتى دارد و ميزان ياسخ ضربان قلب به تمـرين را را

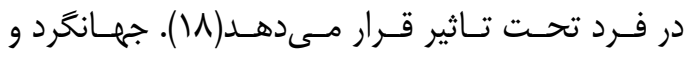

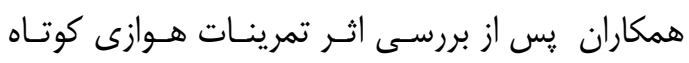

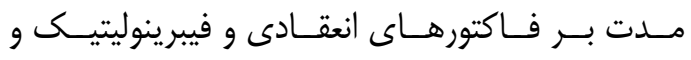

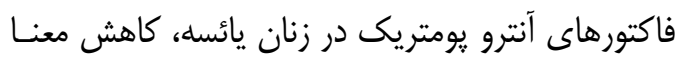

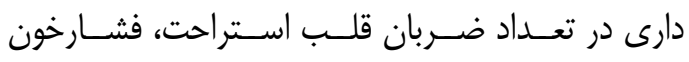
سيستولى وفشارخون دياسـتولى مشـاهده نمودنـــ(19).

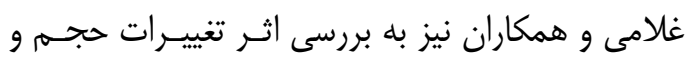

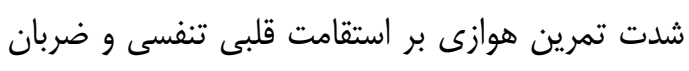

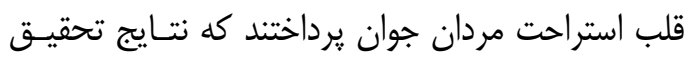

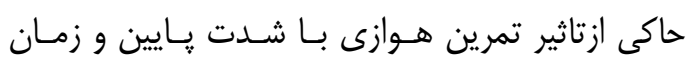

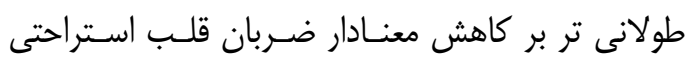

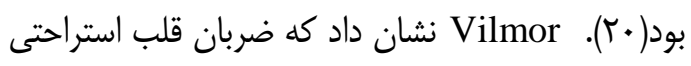

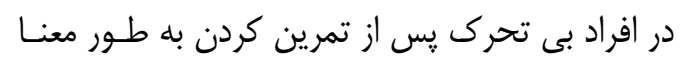

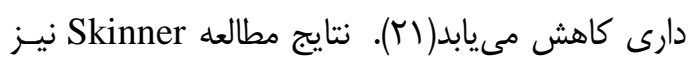

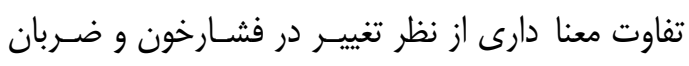

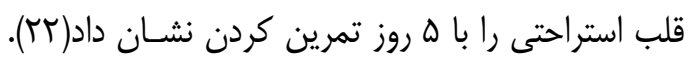

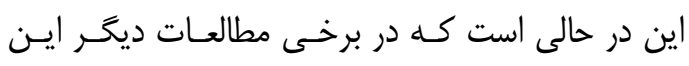

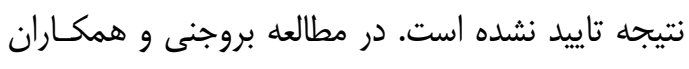

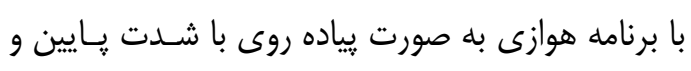

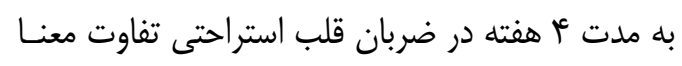

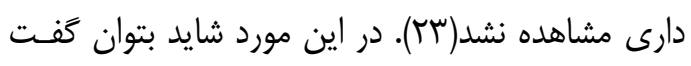
كه كاهش ضربان قلب استراحتى به طور كلى نيـاز بــهـ

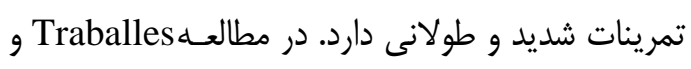

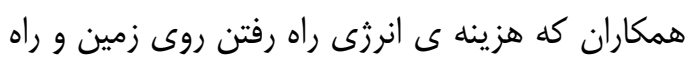

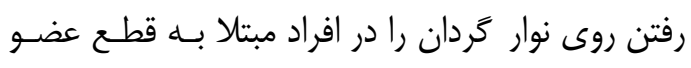

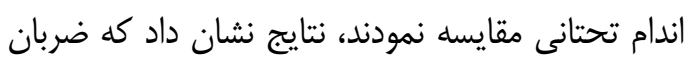

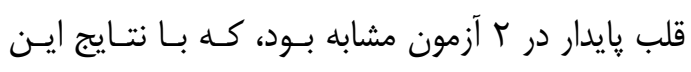

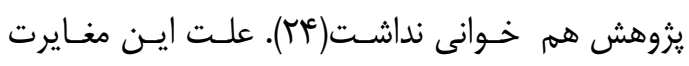

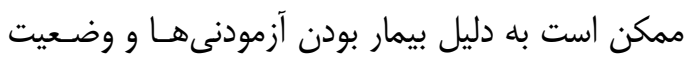

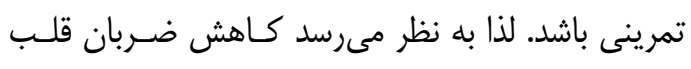

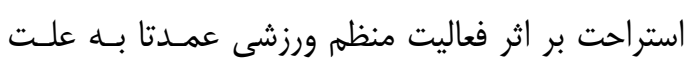

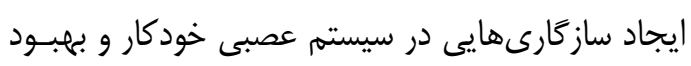

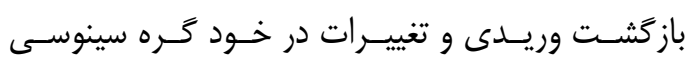

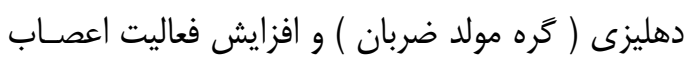

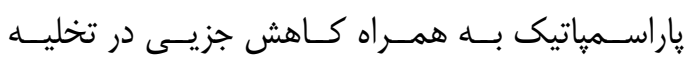

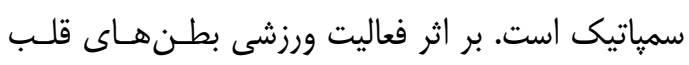

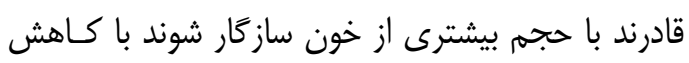


مغايرت مىتواند بيمار بودن آزمودنى ها و شدت تمـرين باشــ. Green و همكـاران مطالعـهاى در مـورد تـاثير

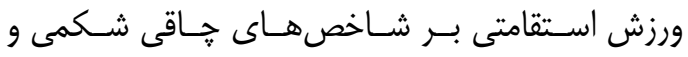

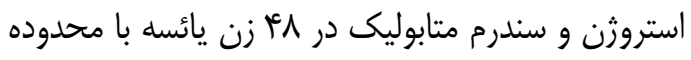

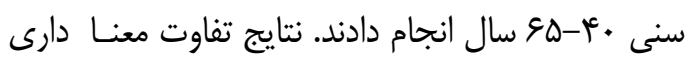
را در شاخصهاى نسبت دور كمـر بـه دور باسـن، دور كمر به قد و درصد هربى با ساير زنان نشان نـدادد(آ).

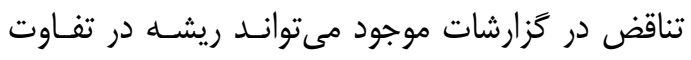

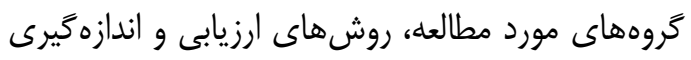

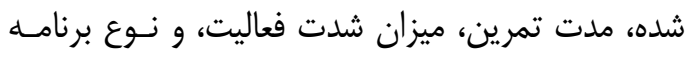

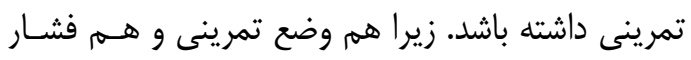

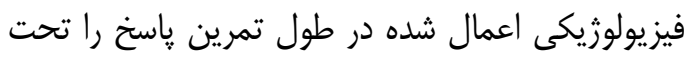

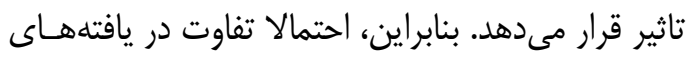

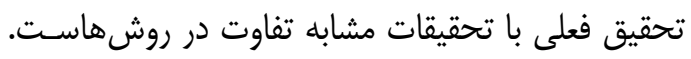

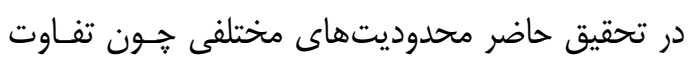

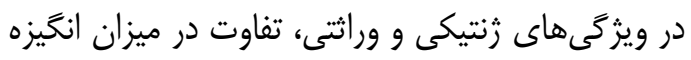
براى اجراى دقيق يروتكل تمرينسى، تفـاوت در ميـزان

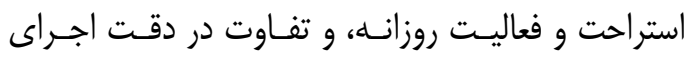

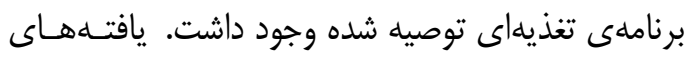

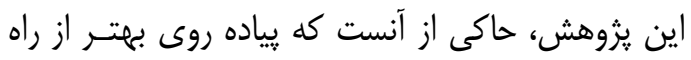

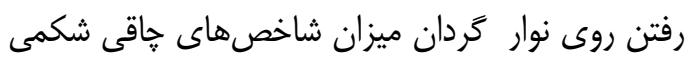

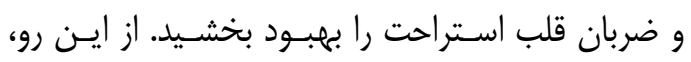

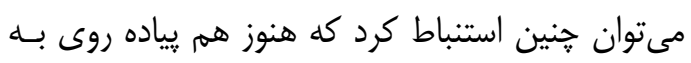

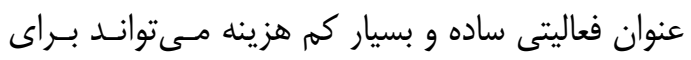

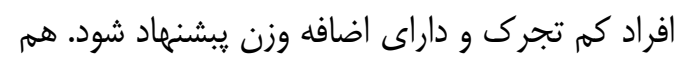

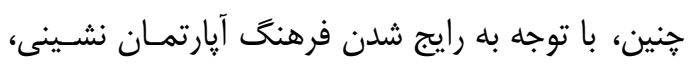

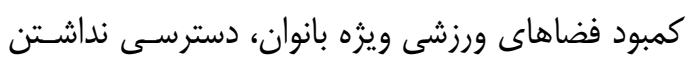

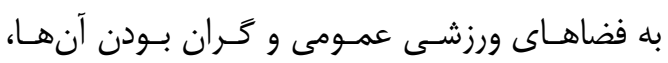

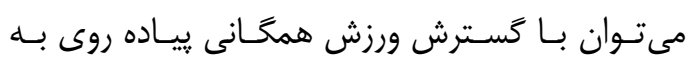

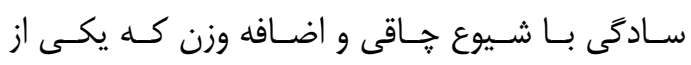
مشكلات سلامت عمومى در سطح جهان است، مقابلـه

\section{سباسگَزارى:}

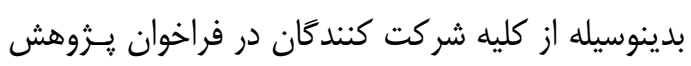

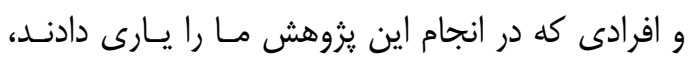

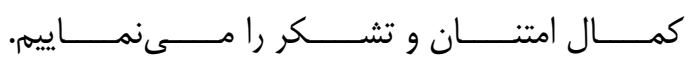

همكاران به دنبال تعيين اثر هشت هفته يياده روى (بـان

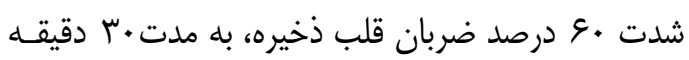

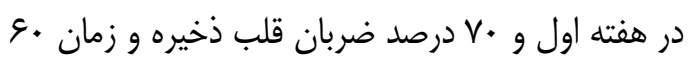

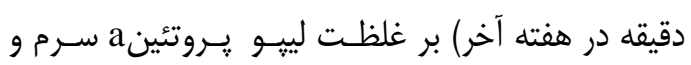

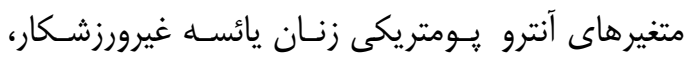

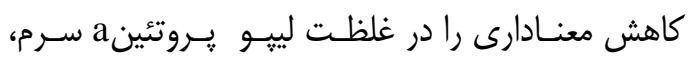
شاخص توده بدنى، درصد هربى بلدن و نسبت دور كمـر

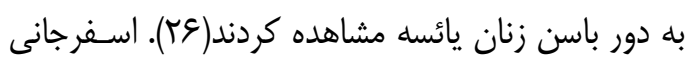

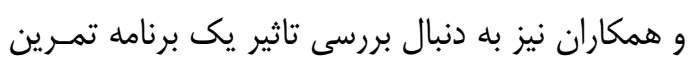

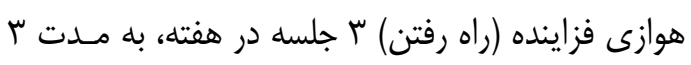

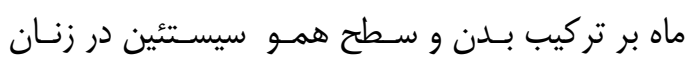

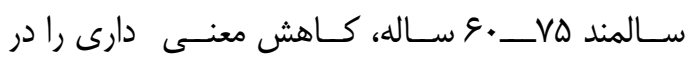

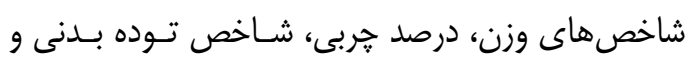

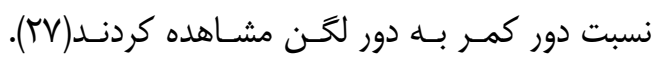

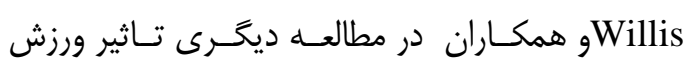

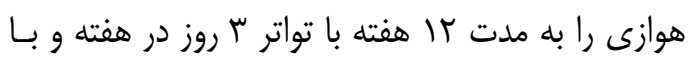

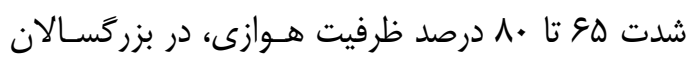

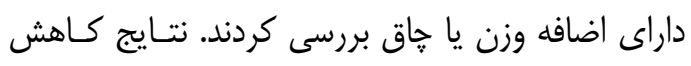

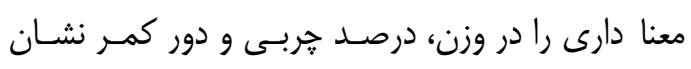

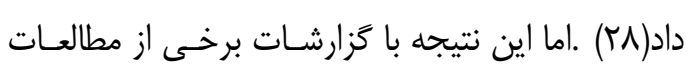

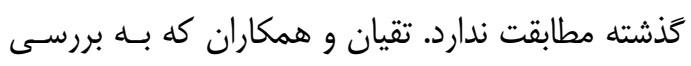

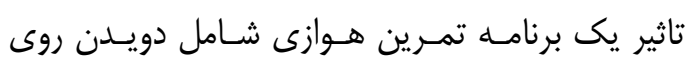

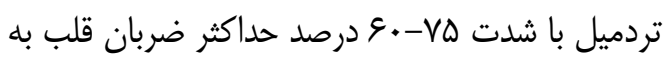

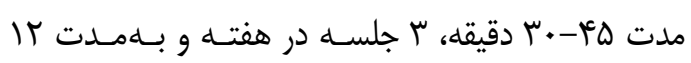

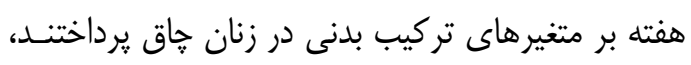

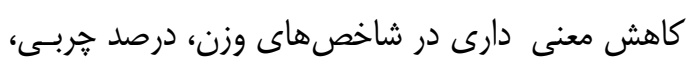

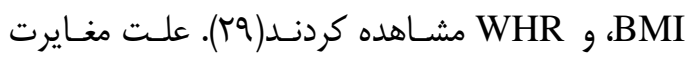

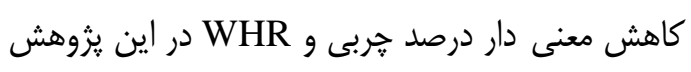

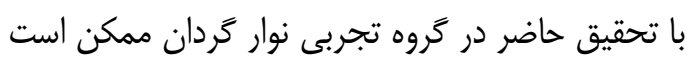

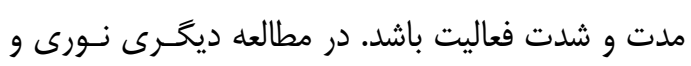

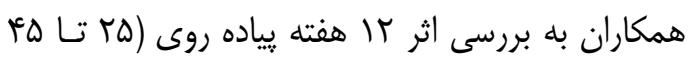

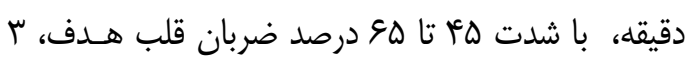

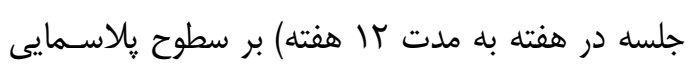

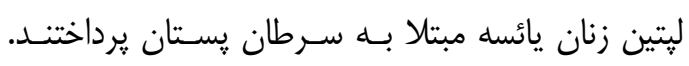

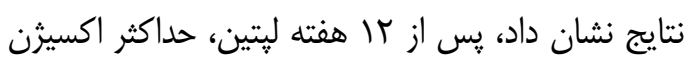
مصرفى، وزن بدن،BMI بين كروه كنترل و تجربى، به ليه

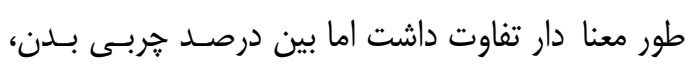

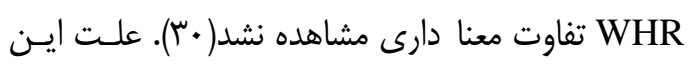




\section{References:}

1.Dashti M H.[ The effect of programmed exercise on body compositions and heart rate of 11-13 years old male students]. ZJRMS 2011; 13: 40-43. (Persian)

2.Mirghafoori HA, Sayadi H, Mirfakhredini HE. [Analysis ofissuesaffectingwomens participationin sports]. J Sport Manage2010; 6: 83-100. (Persian)

3.Marzbanpanah Tu. [Assess the body compositionandrole ofthe weight offemale students]. J Phys Edu Teach Grow2011; 11: 41-3. (Persian)

4.Kaplan Y, Barak Y, Palmonovich E, Nyska M, Witvoruw E. Referent body weight values in over ground walking over ground jogging teardmill jogging and elliptical exercise. J Gait Pos 20014; 39: 558-62.

5.Habibzadeh Na, Rahmani FA, Daneshmandi HA. [The effect of selected walking program on bone mass density body composition and estrogen in obese girls]. J Knowl Health 2009; 4: 8-12. (Persian)

6.Tomas E, Stewart D, Mitchell S, Aiken K, Farina D, Macluso A. Comparison of neural activation and energy cost during teardmill walking with body weight unloding between frail and healthy older women. J Gait Pos 2011;33:356-60.

7.Warabi T, Kato M, Kiriyama K, Yoshida $\mathrm{T}$, Kobayashi N. Treadmill walking and over ground walking of human subjects compared by recording sole floor reaction force. Neurosci Res 2005; 53: 343-8.

8.Nagano H, Begg RK, Sparrow WA, Taylor S. A comparison of treadmill and overground walking effects on step cycle asymmetry in young and older individuals. J Appl Biomech2013; 29:188-93

9.Lee So, Hidler J. Biomechanics of overground vs. treadmill walking in healthy individuals. J Appl Physiol2008; 104:74755.

10.Ceccato JC, De Seze M, Azevedo C, Cazalets JR. Comparison of trunk activity during gait initiation and walking in humans. Plos One 2009; 4: 81-93.

11.Hajihasani AH, Bahrpeyma F, Bakhtiari AH, Taghikhani M. [Effect of exercises downhill and uphill running on serum Adiponectin and Glucose in type-2 diabetic patients]. J GorganUni Med Sci 2012; 3: 52-9. (Persian)

12.Daryaee M. [Ageing and health]. J Gonabad Uni Med Sci2012; 1-28. (Persian) 13.Lippincott W, Wilkins. ACSMs guidelines for exercise testing and prescription. Am Coll Sports Med2005; 92: 173-9.

14.Shafa T. Reliability and validity of Persian version of the physical activity readiness questionnaire in older people in Iran. Tehran Uni Soc Welf Rehabil2013;2:23-8.

15.Chandonnet Na, Saey D, Almeras Na, Marc I. Pregnancy physical activity questionnaire compared with an accelerometer cut point to classify physical activity among pregnant obese Women. J PLoS One 2012; 7:88-95.

16. Fallahi A, Nejatian MU, Gaini AB, Kordy MR, Samadi A. [Comparison of two methods of continuous and intermittent aerobic exercise training on resting heart rate and recovery periodin minutes 1,2,3 patients post GABA]. J Med Coun Islam Rep Iran 2013;29: 29-37.(Persian)

17. Michael A. Jolly Md, Danielle M. Brennan Ms, Leslie Cho. Impact of exercise on heart rate recovery. J Aha 2011;124: $1520-6$.

18.Jarrete A, NovaisI. Nunes H, Puga G, Delbin M, Zanesco A. Influence of aerobic exercise training on cardiovascular and endocrine inflammatory biomarkers in hypertensive postmenopausal women. J Clin Trans Endocrinol2014; 13:108-14.

19.Jahangard T, Torkaman G, Gooshe B, Hedayate M, Dibaj A. [The effect of aerobic exercise on fibrinolyticactivity factors in post menopausal Women ]. J Kowsar Med 2011; 14: 42-7. (Persian)

20.Gholami MA, Sabbaghianrad LE, Abednatanzi $\mathrm{H}$. [The effect of change in volume and intensity of aerobic training on cardiorespiratory endurance in young Males]. J Daneshvar Med 2012; 19:20-31. (Persian)

21.Vilmor JH, Castill DL, Kenney, WL. Physiology of sport and exercise champaign IL. Human Kinetics Publication 2008; P. 119-28.

22.Skinner JS. Physiological response of men to 1,3 and 5 day per week training program. J Red Sport 2005; 57:62-75. 
23.Hosseinyboroujeni M , Farahani Z, Shiri $\mathrm{H}$, AbedSaeedi H, Alavimajdgi, Hamidizadeh HA. [The impact of low intensity aerobic exercise on blood pressure]. J ShahrekordUni Med Sci2009; 9 :14-19. (Persian)

24.Traballesi M, Porcacchia P, Averna T, Brunelli S. Energy cost of walking measurements in subjects with lower liamputations a comparison study between floor and treadmill test. Gait Pos2008; 27: 70-5.

25.Zhang GQ, Zhang W. Heart rate lifespain and mortality risk. Ageing Res Rev2009;8: 52-60.

26.Firozeh Z, Bijeh N, Ebrahimiatri A, Ramesani S. [Effect of 8 week walking programon serum lipoprotein a concentration in non athletemen opausal Women]. J GorganUni Med Sci 2010; 13:30-8. (Persian)

27.Esfarjani F, Taghian F. [Effects of aerobic training on body composition and serum homocysteine in elderly Women]. J Armaghan Danesh 2011; 16:221-32. (Persian)
28.Willis L, Slentz C, Bateman L, Shields T, Piner L, Bales C, Houmard J, Kraus W. Effects of aerobic and or resistance training on body mass and fat mass in overweight or obese adults. J Appl Physiol2012; 113:1831-7.

29.Taghian F, Nikbakht H, Karbasian A. [Effect of aerobic training on plasmaleptin levels in obese Women]. J Res Sport Sci 2010; 4: 45-58.(Persian)

30.Noory R, Karamybanary La, Moghadasi $\mathrm{M}$, Tahmasebi S, Taleye Ab. [The effect of 12 weeks of walking on plasma levels of leptin in postmenopausal Women with breast cancer]. J Sport Biocien 2013; 8: 107-22.(Persian)

31.Green JS, Stanforth PR, Rankinen T, Leon AS, Rao DC, Skinner JS, et al. The effect of exercise training on abdominal visceral fat body composition and indicators of the metabolice syndrome in postmenopausal Women with and without estrogen replacement therapy. J Metabol 2010; 53: 60-92. 


\title{
Comparing the effects of treadmill and ground walking onAbdominal Obesity and Resting heart rate among inactive overweight women
}

\author{
Delfani $Z^{1^{*}}$, Shahidi $F^{1}$
}

(Received: January 9, 2016 Accepted: February 23, 2016)

\begin{abstract}
:
Introduction: Currently, due to the high prevalence of overweight, obesity and modernization of life, walking on a treadmill is welcomed instead of walking on the ground. The aim of the study was to compare the effects of treadmill and ground walking, on abdominal obesity and resting heart rate among inactive overweight womenin Boroujerd.
\end{abstract}

Materials \& methods: This semiexperimental study was conducted on 30 healthy, inactive, overweight andabdominalobesity

womenthatvolunteered to take part in this study in2014. After performing a pretest,the participants were randomly allocated into three equal groups $(n=10)$ : Walkingon theground,walking on a Treadmill, and the control. The walking training program was performed three sessionsper week for eight weeks with $60 \%$ to $85 \%$ of heart rate reserve.To compare the effectof trainingprogram,before and after eight weeks, the resting heart rate and the abdominal obesity were detected using Polar device and WHO classification, respectively. The data were analyzed by ANOVA and SPSS19.

Findings: The results showed a significant decrease in resting heart rate inwalking on the treadmill and ground, respectively $(72.3 \pm 2.90,75.3 \pm 1.94)$ afterthe

trainingprogram $(\mathrm{p}<0.05)$. Butthe abdominal obesity showed a significant decrease single in walkingonthe ground $(\mathrm{p}<0.05)$. There was a significant difference in resting heart rate( 75.46 \pm 3.37 ) among the three groupswhilethere was no significant difference in abdominal obesity among the groupsafterthe training $\operatorname{program}(\mathrm{p}<0.05)$

Discussion \& conclusions: These results indicated that bothtreadmill and ground walkingcan improvetheabdominal obesityand resting heart rate.Walking on ground can promote abdominal obesity than walking on treadmill, so to reduce problems caused obesity and overweight mustbe more emphasis on walking on the ground.

Keywords: Walking, Treadmill, Overweight, Resting heart rate, Abdominal obesity 